Supplement of Clim. Past, 14, 1097-1118, 2018

https://doi.org/10.5194/cp-14-1097-2018-supplement

(C) Author(s) 2018. This work is distributed under

the Creative Commons Attribution 4.0 License.

(c) (1)

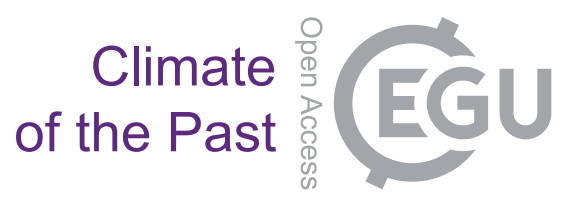

Supplement of

\title{
Tracing winter temperatures over the last two millennia using a north- east Atlantic coastal record
}

Irina Polovodova Asteman et al.

Correspondence to: Kjell Nordberg (kjell.nordberg@marine.gu.se)

The copyright of individual parts of the supplement might differ from the CC BY 4.0 License. 
Supplementary Fig. 1

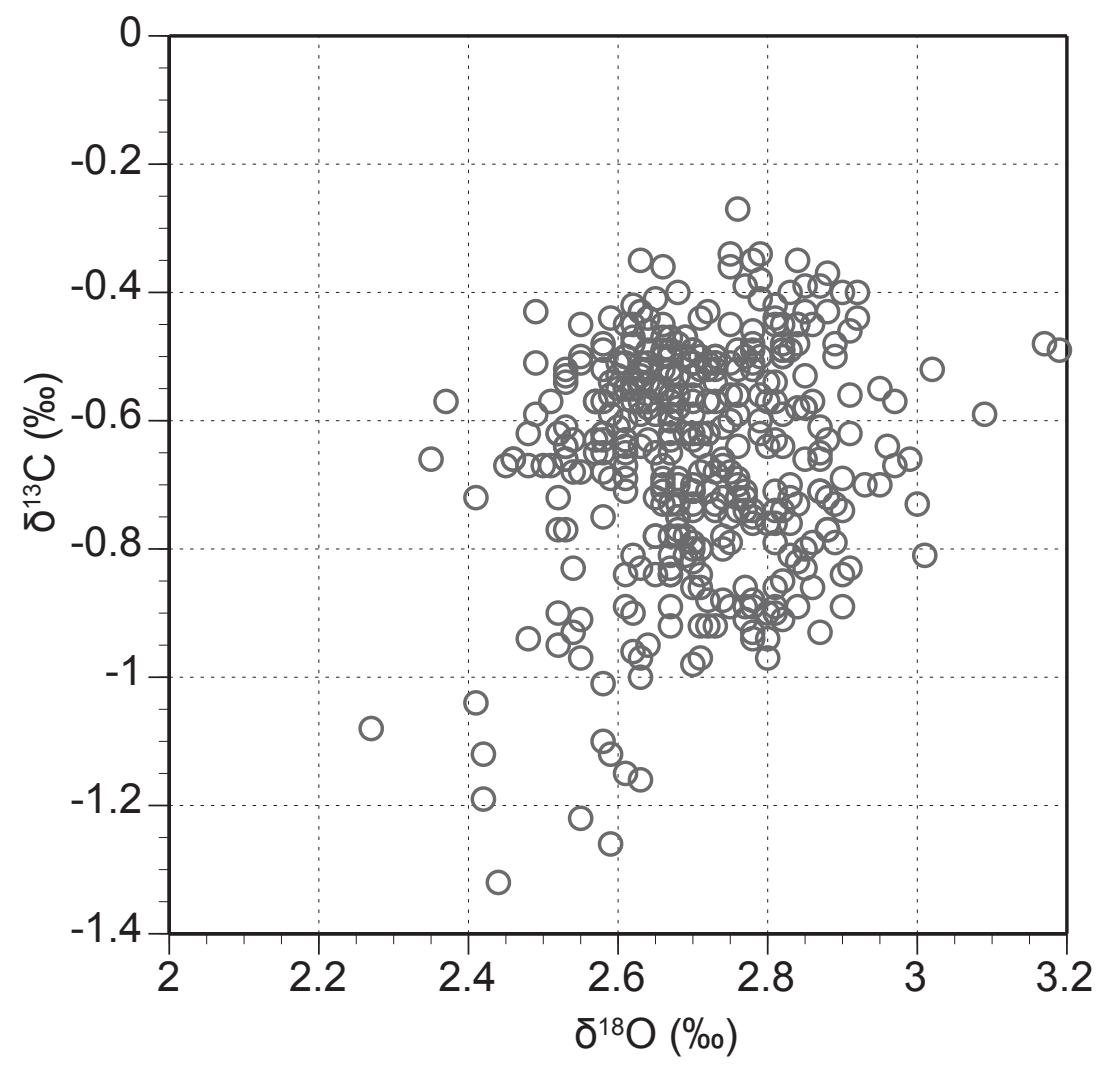

